\title{
RESEARCH IN EDUCATION ITS NECESSITY OF AND IMPORTANCE - A STUDY
}

\author{
Rathnakar. G \\ Department of Mechanical Engineering, ATME College of Engineering, India
}

\begin{abstract}
Research is evidence-based practice or a result that is proven repeatedly when called for, research is search for facts and knowledge. Finding reasons why research is important seems like a question which is obvious, as it is well known that without research every field may attain the state of rigidity or stagnation with no growth and no changes taking place, but many people avoid getting involved in research because of several reasons. The students may not show inclination towards research and the academician could just be doing it for the sake of promotion purposes. Yet, for those who want to learn new things, explore new thoughts and new ideas and involve in creating something new research is a must- whether or not they are members of a learning institution. The revolution in technological growth is the evidence to showcase the need of research in every sector. The results of research can lead to changes in methods and practices, doing research is not just an imperative, but a need. This paper explores the various reasons why research is important in education and what is its contribution in the development of the human growth and its civilization.
\end{abstract}

\section{Keywords:}

Research, Researcher, Education, Technology

\section{INTRODUCTION}

Research is the process of investigating the truth which is not revealed or not known. Research is the process of systematic, rigorous investigation of a situation or problem in order to generate new knowledge, idea or validate existing knowledge [1]. The Advanced Learner's Dictionary of Current English lays down the meaning of research as "A careful investigation or inquiry especially through search for new facts in any branch of knowledge."

- Redman and Mory [2] define research as a "systematized effort to gain new knowledge".

- Slesinger and Stephenson in the Encyclopedia of Social Sciences define research as "the manipulation of things, concepts or symbols for the purpose of generalising to extend, correct or verify knowledge, whether that knowledge aids in construction of theory or in the practice of an art" [3].

- Researchers are engaged in the critical study of original empirical research to learn about cutting edge methods of data collection and analysis. Philosophical assumptions underlying educational enquiry are to be examined. "Creative and systematic work undertaken to increase the stock of knowledge, including knowledge of humans, culture and society, and the use of this stock of knowledge to devise new applications". Research is not just restricted to student and academicians. It is applicable to all the professionals across different streams. Research is equally important for poets and veteran writer also. Research leads to creative thinking, explores the possible ways of finding alternative solutions to an existing problem and enables value addition.

- To carry a research it is necessary to find an interesting topic to discuss and/or to write about should be beyond personal experience. Determining what the general public want to know about or what researchers want others to realize or think about can serve as a problem to do research. Research can lead to lot of solutions to the societal problems including finding possible cures for various diseases and possible methods to prevent these diseases. Research inculcates scientific and inductive thinking and it promotes the development of logical habits of thinking and organization [4].

- Research generally involves problem identification, problem formulation, literature review, analysis or investigation and draw conclusion. Areas where research is predominantly applied are agriculture, food and beverage, manufacturing, healthcare and pharmaceuticals, computer software, semiconductor, information and communication technology, construction, robotics, aerospace, aviation, and energy industries are having high $\mathrm{R} \& \mathrm{D}$ investment and expenditure because it is critical to produce innovate products and improve services.

Young [4] has carried research that can help teachers to understand what works and why, what is the short and long term implications, provide a justification and rationale for decisions and actions, help to build a repertoire to help deal with the unexpected, identify problems, inform improvement and so forth Based on above challenges only one cannot adhered to the research, but the decisions upon evidence is morally sound.

\subsection{FORMS OF RESEARCH}

- Original research: The research that is not based on summery, review and synthesis of earlier publication [5].

- Scientific research: Follows the systematic process of gathering data and harnessing the purpose. This research provides scientific information and theories for the explanation of the nature and the properties of the world [6].

- Research in humanities: Artistic research: is also referred to as 'practice-based research' in this type of research the creative works are considered both the research and the object of research. Applied research: is the scientific study used to solve practical problems. Applied research is used to find solutions to day to day problems, research in the field of medicine to cure illness, develop innovative technologies in medicinal and other engineering disciplines, applied research is more focused on practical issues rather than acquiring knowledge [7]. "Gathering knowledge for knowledge's sake is termed 'pure' or 'basic' research" [4].

- Basic research or pure research: is driven by individual's curiosity or interest. The main motivation is to reveal 
curiosity of man or expand man's knowledge, but not to create or invent something [8].

- Correlation research: deals with the systematic investigation or statistical study of relationships among two or more variables, without necessarily determining cause and effect. It seeks to establish a relation or association or correlation between two or more variables that do not readily lend themselves to experimental manipulation [9].

- Descriptive research: is an accurate portrayal of characteristics of a particular individual, situation, or group. Descriptive research is also known as statistical research [10].

- Ethnographic research: is the investigation of a culture through an in-depth study of the personalities of the culture. It adopts a systematic collection, description, and analysis of data for development of theories of cultural behavior.

- Experimental research: involves the process of determining the objective, systematic, controlled investigation for the purpose of predicting and controlling phenomena and examining probability and causality among selected variables [11].

- Exploratory research: is a type of research conducted for a problem that has not been clearly defined. Exploratory research helps determine the best research design, data collection method and selection of subjects.

- Grounded theory research: is a research approach designed to discover what problems exist in a given social environment and how the persons involved handle them; it involves formulation, testing, and reformulation of propositions until a theory is developed [8] [9].

- Historical research: is a research that involves analysis of event that occurred in the past.

- Phenomenological research: an inductive, descriptive research approach developed from phenomenological philosophy; its aim is to describe an experience as it is actually lived by the person [12].

On a broader perspective, all researches can be classified into two groups:

- Qualitative research: is research dealing with phenomena that are difficult or impossible to quantify mathematically, such as beliefs, meanings, attributes, and symbols Qualitative researchers aim to gather an in-depth understanding of human behavior and the reasons that govern such behavior. The qualitative method investigates the why and how of decision making.

- Quantitative research: refers to the systematic empirical investigation of any phenomena via statistical, mathematical or computational techniques. The objective of quantitative research is to develop and employ mathematical models, theories and/or hypotheses pertaining to phenomena.

\section{PROBLEM DEFINITION}

The need of research in education is recognized by collecting information from various primary and secondary sources. The initiation of the problem was based on the current academic scenario in school education and based on the curriculum being followed in technical and medical institutions. To emphasize and address the need of why research in education, what is its benefits, what is educational research, to address the need for continued research, to understand the contributions of research, and to ensure the need of research for the future prospects of the educational institutions.

\section{METHODOLOGY}

The current problem is analyzed by collecting various data from primary and secondary sources. To analyze the data various statistical tools like graphs and other illustrative technique is adopted.

- To initiate with the problem a detailed questionnaire was prepared.

- This questionnaire was circulated to a selected sample and detailed feedback was obtained from the selected sampling.

- After obtaining the detailed sampling using various illustrative methods the data is being presented in tabular and graphical methods.

- Various inferences and appropriate conclusions were drawn to summarize the findings.

\section{OBJECTIVES}

- To understand and know the need of research and its importance in education.

- To understand the various methods of carrying the research.

- To evaluate the effect of research in education.

- To project the probable benefits that may be derived by implementing research component in education.

- To evaluate the gains by implementing research in education system.

\subsection{REASONS THAT DRIVE RESEARCH}

The following is the list that addresses the various reasons that drive the research in the educational institutions, the following sample questions (few set) were posed in the questionnaire:

- Why research in education?

- What is educational research?

- What is the Need for continued research?

- What is the Contributions of research in education? Need of research for the future.

\subsection{INSTITUTIONS ADOPTING RESEARCH IN THEIR EDUCATION}

The Fig. 1 shows the current trend followed in educational institutions.

It is observed that more than $64 \%$ of the educational institutions follow the conventional education system and around $34 \%$ of the educational institutions have switched over to the new trend of having research component in their curriculum.

The educational institutions have adopted the conventional methods of teaching and it is observed that the educational institutions have limitations to take up necessary initiatives to take 
a required change which has forced the institutions to follow the conventional education methods.

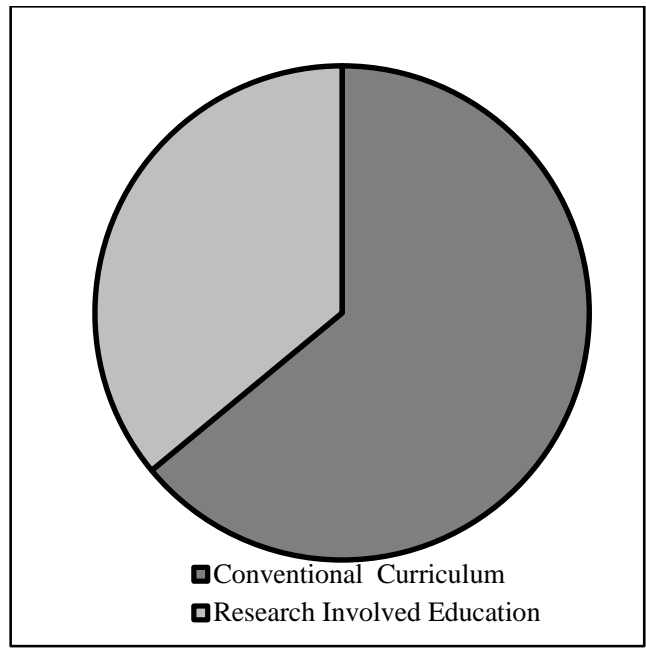

Fig.1. Institution adopting research in curriculum

\subsection{ENHANCE KNOWLEDGE, BUILD LEARNING, INNOVATION}

The basic reason for conducting research is to have an insight into a specific topic and to see that there is a fair chance of enhancing the existing knowledge on that specific topic and further supported with the aid of the previous studies.

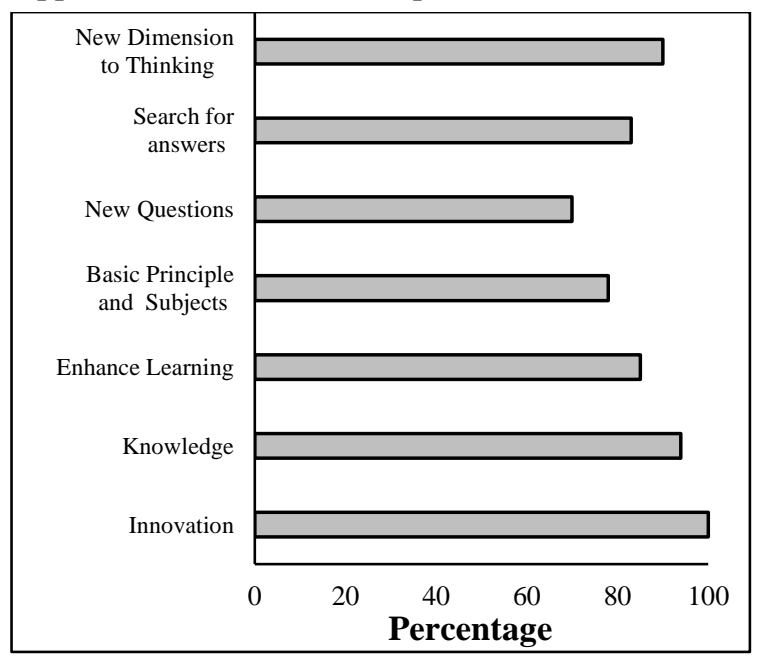

Fig.2. Benefits of Research in Education

From the Fig.2, it is observed and found that the research will lead and enhance some of the parameters such as new dimensions to thinking, tend to search answers, raises new questions, helps understand the basic principles and subjects in a better manner, research will leads to enhanced learning of a subject and concept, will enhance knowledge and leads to innovation. Over all it is observed that there is a remarkable enhancement and benefits related to all the parameters under consideration.

\subsection{MEANS TO UNDERSTAND VARIOUS ISSUES}

Research can reveal some of the issues that were not known earlier and can raise new questions and lead to new investigations.

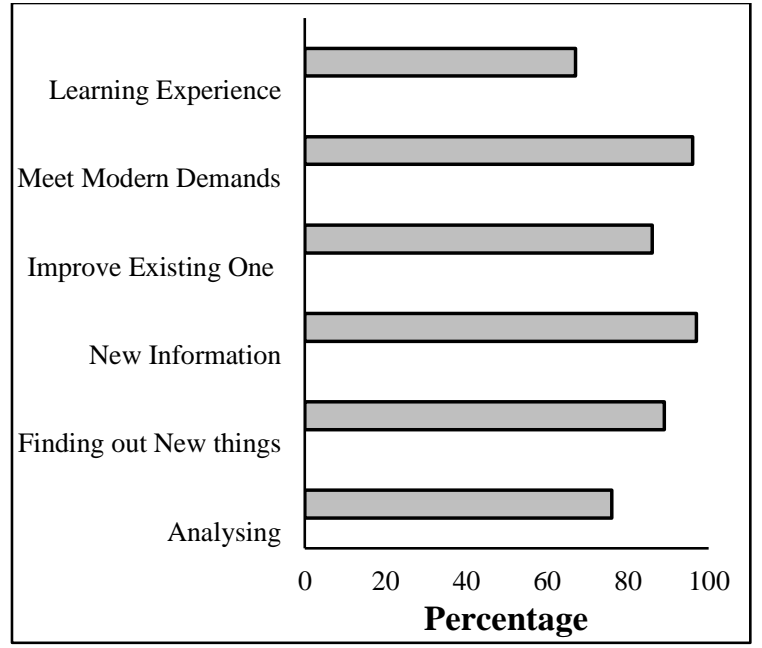

Fig.3. Means to understand various issues

The implementation of research in education will open up various avenues to carry out analysis, helps find new things, new information, improve existing things and information, will prepare to meet modern demands and learning abilities.

\subsection{RESEARCH IN INSTITUTIONS LEADS TO}

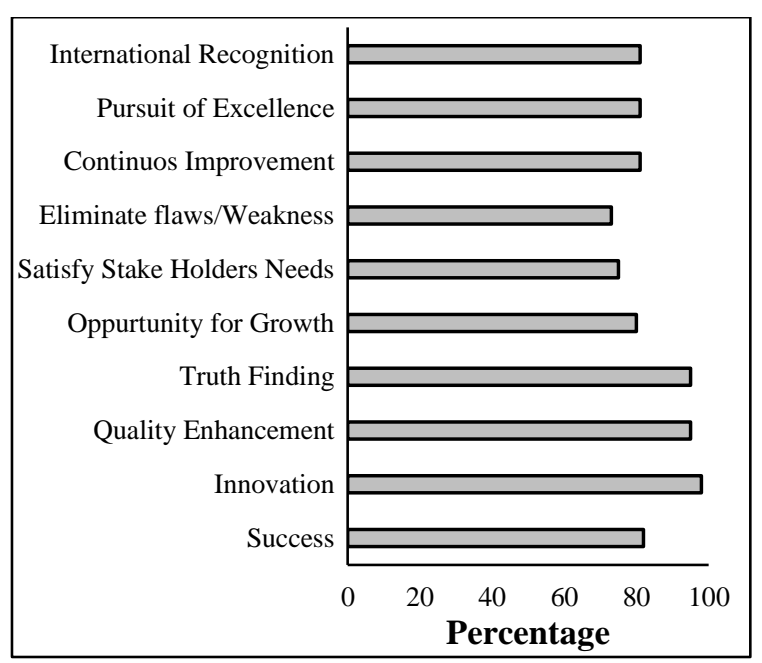

Fig.4. Changes in educational system

From the Fig.4, it is clearly evident that the introduction of research in educational system can lead to various changes in the education leading to enhanced innovation, success, enhancement in quality of product and also in quality of life, helps find truth, enhance the opportunity for growth for the organizations, leading to continuous improvement by eliminating flaws and allows excellence in diverse fields and may bring in international recognition.

\section{CONCLUSIONS}

The current education system needs a transformation and drastic changes to be incorporated in this context the present paper makes an attempt to sensitize the issue of the importance of the research in every sector of the education system. The adoption and 
implementation of research based education in primary and high schools, colleges, technical educational institutions like engineering, polytechnics and in medical education institutions will bring in lot of changes in the current curriculum, enhancing the thinking process leading to learn and visualize the facts in a different dimensions that focuses on leading the educational program towards attaining the required success, innovation, quality enhancement, truth finding, opportunity for growth, satisfy stakeholder's needs, eliminate flaws, continuous improvement, leading to international recognition. The research based education leads to innovation in education system. Overall it can be concluded that the implementation of the research based teaching learning will benefit both student community and society at large.

\section{REFERENCES}

[1] A.S. Horbny and J. Crowther, “Advanced Learner's Dictionary of Current English", Oxford University Press, 1952.

[2] L.V. Redman and A.V.H. Mory, "The Romance of Research", ACS Publication, 1934.

[3] R.A. Seligman, "The Encyclopaedia of Social Sciences", MacMillan Press, 1930.

[4] Pauline V. Young, Calvin F Schmid and Herbert Blumer, "Scientific Social Surveys and Research: An Introduction to the Background, Content, Methods and Analysis of Social Studies", Literary Licensing, 2012.

[5] P.A. Alexander and F.J.R.C. Dochy, "Conceptions of Knowledge and Beliefs: A Comparison across Various Cultural and Educational Communities", American Educational Research Journal, Vol. 32, No. 2, pp. 413-442, 1995.

[6] C.R. Kothari, "Research Methodology, Methods and Techniques", $2^{\text {nd }}$ Edition, New Age International Publishers, 2014.

[7] Russell L. Ackoff, "Scientific Method Optimizing Applied Research Decisions", John Wiley and Sons, 1962.

[8] T.S. Wilkinson and P.L. Bhandarkar, "Methodology and Techniques of Social Research", Himalaya Publishing House, 1979.

[9] B.N. Ghosh, "Scientific Methods and Social Research", Sterling Publishing, 1982.

[10] John W. Best and James V. Kahn, "Research in Education", $5^{\text {th }}$ Edition, Prentice-Hall, 1986.

[11] Mary Beckman and Nancy Hensel, "Making Explicit the Implicit: Defining Undergraduate Research", Council on Undergraduate Research, Vol. 29, No. 4, pp. 40-44, 2009.

[12] OECD Frascati Manual, "Guidelines for Collecting and Reporting Data on Research and Experimental Development", 2015. 